\title{
Public Health Perspectives as the COVID-19 Vaccines Enter Production and Distribution Phases
}

\section{Rabiu Momoh ${ }^{*}$ and Mohammed Rahman \\ William Harvey Hospital, Ashford, Kent, United Kingdom}

One of the high points in a year marred by the COVID-19 pandemic is the news of the COVID-19 vaccine becoming available to the world [1]. Already, more than a million deaths have been recorded due to the COVID-19 virus and its severe complications [2]. Many world regions are having to create programs to cater to the long-term sequelae of severe COVID-19 manifestations in other individuals, described by the term 'Long COVID' in the United Kingdom [3]. The socio-economic impact of this pandemic on life around the world continues to be alluded to [4]. While the COVID-19 vaccines' potentials are being celebrated, corollaries can be made to other public health concerns worth shedding light on.

If the vaccines achieve the desired effect of protecting vulnerable and frontline workers, and maybe the general world population from this infection, then a lot would stand to be gained in returning the world to the normalcy of a pre-COVID-19 era, where business and international travels were in full swing. Relationships that were constrained or restrained between individuals, groups, businesses, communities, or nations will be reconsidered. We may be able to markedly reduce this virus's infection rate and its accompanying death toll and, maybe soon, we can eradicate this virus as was achieved with the smallpox virus.

The urgency with which the available COVID-19 vaccines were produced and rolled-out are quite remarkable (Figure 1). Looking back in history, the development of vaccines for major world diseases such as smallpox, bubonic plague, typhoid fever, influenza, polio, anthrax, Varicella, Hepatitis B, Measles, Mumps, and Rubella virus, among others, probably took years to decades. Some required centuries before these vaccines could be developed [5]. These show that we may have advanced with the wherewithal and technology to respond to world diseases where the will-to-do is high.

This brings to the reasoning that we are still plagued by a world where a desire to eradicate diseases such as HIV/AIDS, malaria, and Ebola continues to rage or ravage in different world areas. The same political and pharmaceutical will can be extended to these other world health challenges. Where feasible, the political will gained towards the production of the COVID-19 vaccine could be directed to other sustainable development goals (e.g., the drives to eradicate poverty and extreme poverty, ensure education coverage, ensure environmental sustainability, among other goals).
The potential problems of availability and access to this COVID-19 vaccine and the cost implication to governments of nations (especially in developing and less-developed world areas) would remain a challenge and a talking point [6]. An illustration of these problems is depicted in (Figure 2). While the world awaits the improved COVID-19 vaccine coverage, we can celebrate the gains of a rapid response to vaccine production in the face of a deadly pandemic.

\section{Conflict of Interest}

The authors declare that they have no conflict of interest.

\section{Funding Source}

None.

\section{References}

1. Elisabeth M (2020) Vaccinating the UK: How the Covid vaccine was approved, and other questions answered. BMJ 371:4759.

2. (2021) WHO Coronavirus Disease (COVID-19) Dashboard.

3. Elisabeth M (2020) Covid-19: What do we know about "long Covid"? BMJ 370: 2815.

4. Maria N, Zaid A, Catrin S, et al. (2020) The socio-economic implications of the coronavirus pandemic (COVID-19): A review. Int J Surg 78: 185-193.

5. Natalie C (2020) How long it took to develop 12 other vaccines in history.

6. Helene G, William F, Lisa B, et al. (2020) Framework for equitable allocation of COVID-19 vaccine. The National Academies Press, Washington, DC, USA.

*Corresponding author: Dr. Rabiu Momoh, William Harvey Hospital, Ashford, Kent, United Kingdom

Accepted: February 13, 2021

Published online: February 15, 2021

Citation: Momoh R, Rahman M (2021) Public Health Perspectives as the COVID-19 Vaccines Enter Production and Distribution Phases. Ann Public Health Reports 5(1):170-171 


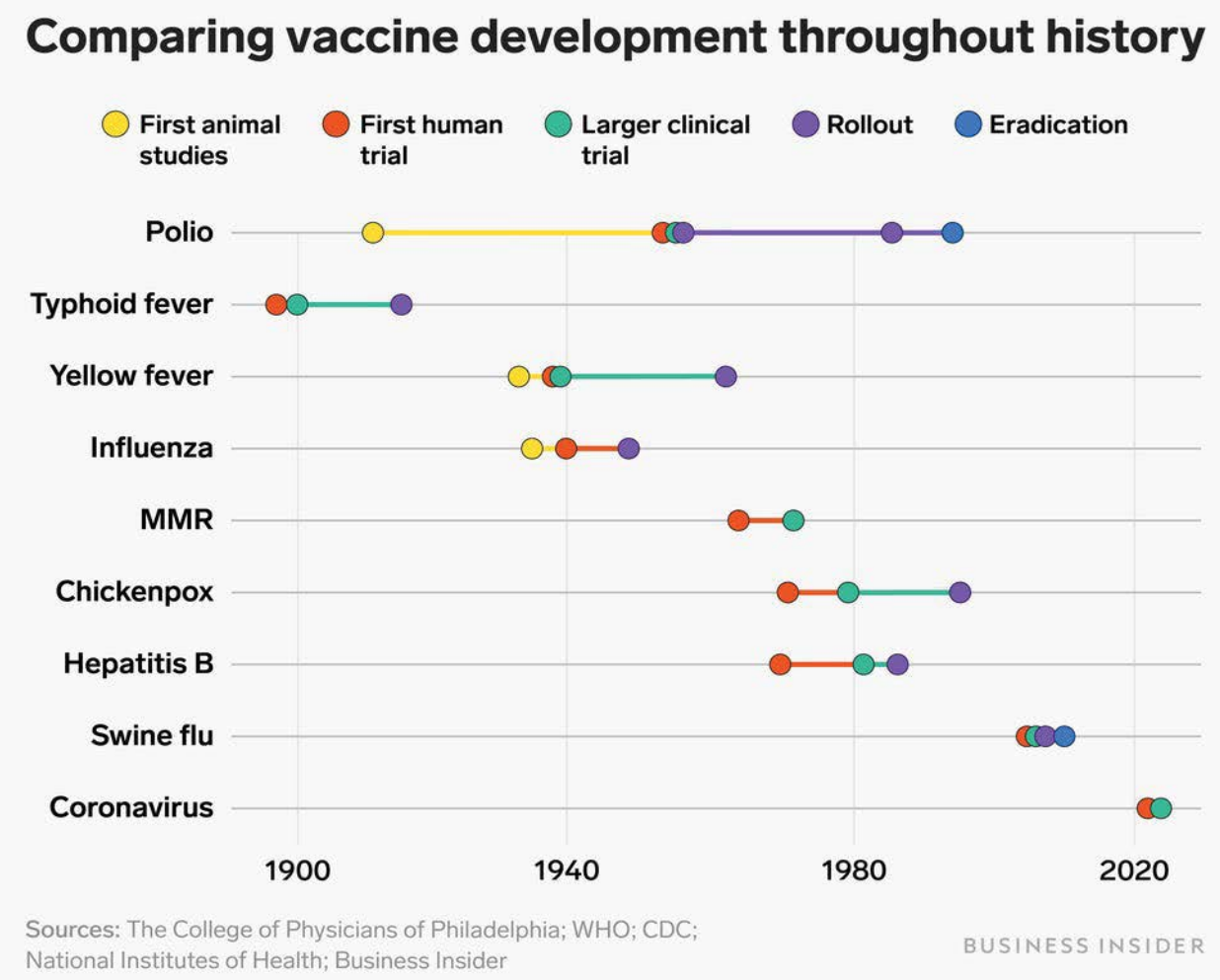

Figure 1: Describing timeline of development of vaccines, their rollouts and disease eradication in human history.

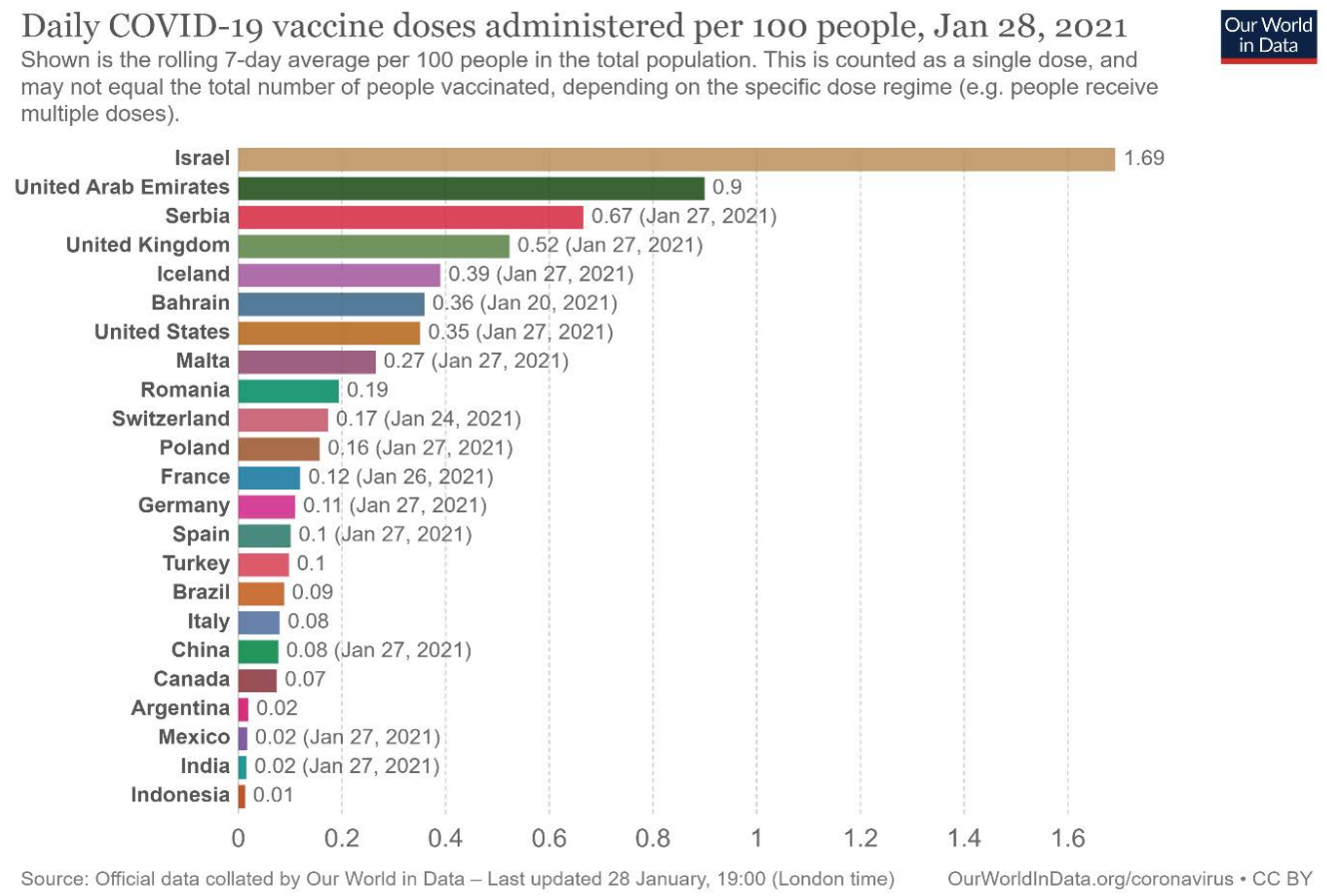

Figure 2: Comparative daily COVID-19 vaccinations by countries.

DOI: $10.36959 / 856 / 515$

Copyright: (C) 2021 Momoh R, et al. This is an open-access article distributed under the terms of the Creative Commons Attribution License, which permits unrestricted use, distribution, and reproduction in any medium, provided the original author and source are credited. 